\title{
A coupled movement and bioenergetics model to explore the spawning migration of anchovy in the Bay of Biscay
}

\author{
Politikos Dimitrios ${ }^{1}$, Huret Martin ${ }^{1, *}$, Petitgas Pierre ${ }^{2}$
}

\author{
${ }^{1}$ Ifremer, STH/LBH, B.P. 70, 29280 Plouzané, France \\ ${ }^{2}$ Ifremer, EMH, rue de l'île d'Yeu, B.P. 21105, 44311 Nantes Cedex 03, France \\ * Corresponding author : Martin Huret, Tel.: +33 0298224136 ; fax: +33 0229008547 ; \\ email address : martin.huret@ifremer.fr
}

\begin{abstract}
:
Adult anchovies in the Bay of Biscay perform north to south migration from late winter to early summer for spawning. However, what triggers and drives the geographic shift of the population remains unclear and poorly understood. An individual-based fish model has been implemented to explore the potential mechanisms that control anchovy's movement routes toward its spawning habitats. To achieve this goal, two fish movement behaviors - gradient detection through restricted area search and kinesis - simulated fish response to its dynamic environment. A bioenergetics model was used to represent individual growth and reproduction along the fish trajectory. The environmental forcing (food, temperature) of the model was provided by a coupled physical-biogeochemical model. We followed a hypothesis-testing strategy to actualize a series of simulations using different cues and computational assumptions. The gradient detection behavior was found as the most suitable mechanism to recreate the observed shift of anchovy distribution under the combined effect of sea-surface temperature and zooplankton. In addition, our results suggested that southward movement occurred more actively from early April to middle May following favorably the spatio-temporal evolution of zooplankton and temperature. In terms of fish bioenergetics, individuals who ended up in the southern part of the bay presented better condition based on energy content, proposing the resulting energy gain as an ecological explanation for this migration. The kinesis approach resulted in a moderate performance, producing distribution pattern with the highest spread. Finally, model performance was not significantly affected by changes on the starting date, initial fish distribution and number of particles used in the simulations, whereas it was drastically influenced by the adopted cues.
\end{abstract}

\section{Highlights}

- Both temperature and food are needed to perform anchovy spawning migration in Biscay. Gradient search works better than kinesis in our regional fish movement model. $\rightarrow$ The model proposes timing for migration, consistent with changes in the environment. The model verifies that southward migration is profitable for fish bioenergetics.

Keywords : Individual-based model, Behavioral movement, Dynamic Energy Budget, Anchovy, Bay of Biscay 


\section{Introduction}

Small pelagic fish undergo migrations between distinct habitats to support their feeding and reproduction requirements. These migrations represent an efficient strategy for the maximization of fitness at individual and population scale and are highly driven by seasonal environmental variations (Checkley et al., 2009; Giannoulaki et al., 2014). Moreover, geographic shifts of fish distributions to their spawning grounds are indispensable to ensure the survival of offsprings and consequently, recruitment success (Fréon et al., 2010; Ward et al., 2003). Identifying the conditions that define the temporal coincidence between fish physiological needs and these displacements to suitable areas is crucial for understanding fish migration dynamics (Chen et al., 2010; Lo et al., 2010) and investigate their response to future climate changes (Okunishi et al., 2012a) .

Adult anchovies in the Bay of Biscay (BoB) exhibit seasonal movements and their distribution patterns have been documented in ICES (2010, Chap. 8). Spawning primarily occurs over spring to summer in highly productive areas such as river plumes, shelf break fronts, and oceanic eddies mostly found in the southeast corner of the bay where large anchovy aggregations are observed (Motos et al., 1996, Koutsikopoulos and Le Cann, 1996). After spawning, dispersal to the north, especially for larger fish, has been confirmed by the analysis of fishing activity (Uriarte et al., 1996) and reanalysis of anchovy presence data derived from PELGAS surveys (Petitgas et al., 2011). However, the exact mechanisms, as well as what triggers the starting and ending period of these geographic shifts remain uncertain and poorly understood (Petitgas et al., 2013). As anchovy fishery in the BoB interacts strongly with anchovy distribution (ICES, 2014; Uriarte et al., 1996), and given that management strategy evaluation is strongly sensitive to fish seasonal distribution (Lehuta et al, 2013), understanding migration ecology is key in proposing adequate spatio-temporal management strategies.

Simulating fish movement through spatially explicit individual-based models (IBMs) has been proven an efficient approach for exploring the link between fish migration dynamics and their living conditions. Indeed, IBMs have been successfully used to identify spawning migration routes (Barbaro et al., 2009; Okunishi et al., 2009), predict recruitment (Okunishi et al., 2012b; Xu et al., 2013), study the influence of physical environment on fish biomass interannual variability (Politikos et al., 2014; Rose et al., 2015) and investigate the impacts of climate change on fish growth and distribution patterns (Huse and Ellingsen, 2008; Ito et al., 2013). 
The ultimate goal of the paper is to identify the key environmental drivers that control BoB anchovy's southward movement for spawning. To this end, we developed a horizontal two-dimensional IBM model through which we tested a series of hypotheses. Under different rules of swimming, we simulated fish movement following conceptually two behavioral approaches, i.e. the gradient area search (Politikos et al., 2014; Tu et al., 2012) and kinesis (Okunishi et al., 2009; Rose et al., 2015). The bioenergetic model developed in Huret et al. (submitted) was used to depict individual growth and reproduction along anchovy's trajectory and define behavioral cues based on fish physiological needs. Sea water temperature and zooplankton fields were extracted from a three dimensional lower trophic model and then used as environmental forcing to trigger anchovy's response to its dynamic spatial environment. The IBM model was implemented for adult stage. Its skill was examined by comparing model results with distribution maps derived from seasonally acquired survey data. A reference run and ten additional experiments were performed to compare the simulated fish spatial patterns under several behavioral and computational assumptions. In the discussion section, we analyze the implications of simulation outputs and document the model limitations.

\section{Materials and Methods}

\subsection{Anchovy bioenergetics}

The configuration of the bioenergetic model developed in Huret et al. (submitted) was used to simulate anchovy's growth and spawning activity. It is based on the Dynamic Energy Budget (DEB) theory (Kooijman, 2010) which tracks the energy fluxes within the fish organism through the physiological processes of assimilation, maintenance, maturation, growth and reproduction. For the analysis of our results, we used the model products which describe fish length, fish wet weight, fish energy and the energy allocated to reproduction (Huret et al., submitted). The main inputs of the bioenergetic model are: food density and temperature, which were provided by the forcing environment described in section 2.2.

\subsection{Forcing environment}


ECO-MARS3D (Lazure and Dumas, 2008) is a coupled physical-biogeochemical model which describes the general patterns of hydrodynamics and lower trophic dynamics at the seasonal and multidecadal scale in the BoB (Huret et al., 2013). The current configuration has a numerical grid of 4x4 km resolution in the horizontal and 30 sigma layers in the vertical and it provides the living conditions of anchovy. Hence, three day climatology of temperature fields during 1982-2007 and a weekly climatology of two zooplankton groups (micro- and mesozooplankton) averaged over 2001-2005 were extracted and used as the forcing inputs for the IBM model. Zooplankton and temperature fields define the fish consumption rates and metabolic requirements in the DEB model, as well as the movement decision rules (see section 2.3).

\subsection{Movement}

Individual fish behaviour is controlled by a diversity of external (environmental cues, density dependent processes, inter-specific relations) and internal factors (physiology, sociability, age) (Planque et al., 2011). Furthermore, bigger fish, conversely to early life stages, can also actively direct their own locomotion and shift their geographical distributions in order to reach optimum habitat conditions (Lett et al., 2009). These complexities and uncertainties on how individuals discern and react to their environment have led in the development of different approaches for representing behavioral movement within numerical models, like restricted area search, kinesis, event-based and run and tumble (Watkins and Rose, 2013). In terms of mathematical structure, these approaches are considered as biased correlated random walk, where the change in fish direction may depend on various cues such as currents, prey availability, temperature, salinity and fish condition (Humston et al., 2004; Okunishi et al., 2009; $\mathrm{Xu}$ et al., 2013). In this section, we identify the potential cues for our case study and describe the adopted movement algorithms.

\subsubsection{Potential cues}

In autumn, adult anchovy is distributed in northern BoB for feeding while in spring the major spawning grounds are located in the south (ICES, 2010). The shift of the population from north to south is supposedly driven by the search of optimum oceanographic conditions and high productivity areas in an effort to cover the physiological needs of a multiple batch spawner and the survival of offsprings (Petit- 
gas et al., 2013). However, the exact drivers and timing are uncertain. Thus, possible cues were considered based on existing hypothesis.

Anchovy spawning to the southern part of the bay seems to be triggered by the warming of surface water (Koutsikopoulos and Le Cann, 1996) following the progression of the associated stratification, which starts in April in the south and extends progressively to the north (Motos et al., 1996). Meanwhile, planktonic spring production increases reaching its highest biomass values during late spring and summer (Poulet et al., 1996). Based on the aforementioned information and following our hypothesis testing strategy, zooplankton and sea surface temperature were tested as potential cues to induce north to south movement of anchovy.

Ultimately, searching for areas which maximize fish physiological response has also been proposed to be very effective at reproducing observed distributions. For instance, the growth rate was considered as the key driver of fish behavior in order to simulate the migration and growth patterns of sardine in the western North Pacific (Okunishi et al., 2012) and investigate the influence of physical and plankton variability on Peruvian anchovy recruitment (Xu et al., 2013). In our study, the component of the DEB model which calculates the remaining energy that goes for somatic growth after covering maintenance costs (Huret et al., submitted) represented the index of optimum habitat search, as it integrates concurrently the effects of food, temperature and physiological requirements.

\subsubsection{Movement Algorithms}

The movement algorithms were built using the Lagrangian approach which permits the individual fish tracking in the continuous space of a grid (Okunishi et al., 2012b; Watkins and Rose, 2013). The position of each individual $\left(x_{k+1}, y_{k+1}\right)$ at time $k+1$, which was at $\left(x_{k}, y_{k}\right)$ at time $k$, is updated following the equations:

$$
\begin{aligned}
& x_{k+1}=x_{k}+\left(D_{x_{k}}+R_{x_{k}}\right) \times \Delta \\
& y_{k+1}=y_{k}+\left(D_{y_{k}}+R_{y_{k}}\right) \times \Delta
\end{aligned}
$$

where $\left(D_{x_{k}}, D_{y_{k}}\right)$ define the oriented movement in $x, y$ dimensions, $\left(R_{x_{k}}, R_{y_{k}}\right)$ denote the random component and $\Delta t$ is the time step. 


\section{Gradient Area Search (GAS)}

The GAS algorithm is based on gradient detection (Tu et al., 2012). Hence, from the current fish location, individuals are able to detect the environment in neighbor cells both in $x, y$ directions and then move towards the cell with the highest quality at a specified velocity. The orientated part in Eq. (1) is calculated as,

$$
D_{x}=F_{\mathrm{SS}} \rtimes G_{x}, D_{y}=F_{\mathrm{SS}} \mathbb{G}_{y},
$$

where $F_{\mathrm{SS}}=F_{\mathrm{SS}}^{\text {base }}+E_{\mathrm{SS}} \times \varepsilon$ is the maximum sustainable fish swimming speed $\left(\mathrm{ms}^{-1}\right), F_{\mathrm{SS}}^{\text {base }}$ is the baseline swimming speed expressed in body length per unit time ( 1.3 body length $\left.\mathrm{s}^{-1}\right), E_{\mathrm{SS}}=0.1 \times F_{\mathrm{SS}}^{\text {base }}$ is the added degree of random noise and $\varepsilon$ is a uniform random number between -1 and 1 . The $G_{x}, G_{y}$ are unit vectors, which define the fish direction as follows:

$$
G_{x}=\frac{C_{x}}{\mathrm{MG}}, G_{y}=\frac{C_{y}}{\mathrm{MG}},(3)
$$

where $C_{x}, C_{y}$ are the cue gradients in $x, y$ dimensions and $\mathrm{MG}=\sqrt{C_{x}{ }^{2}+C_{y}{ }^{2}}$ is the corresponding magnitude. Assuming a combined effect of the mean zooplankton (Z) over 0-40m and sea surface temperature (SST), the cue gradients $\left(C_{x}, C_{y}\right)$ were determined by the weighted sum:

$$
\begin{aligned}
& C_{x}=a_{\mathrm{RA}} \chi_{x}^{n}+\left(1-a_{\mathrm{RA}}\right) 8 \mathrm{ST}_{x}^{n}, 0 \quad a_{\mathrm{RA}} \quad 4 \\
& C_{y}=a_{\mathrm{RA}} \chi \mathrm{Z}_{x}^{n}+\left(1-a_{\mathrm{RA}}\right) 8 \mathrm{ST}_{y}^{n},
\end{aligned}
$$

where $\left(\mathrm{Z}_{x}^{n}, \mathrm{Z}_{x}^{n}\right),\left(\mathrm{SST}_{x}^{n}, \mathrm{SST}_{y}^{n}\right)$ are the normalized gradients of $\mathrm{Z}$ and SST cues respectively and $a_{\mathrm{RA}}$ is the term which parameterizes their interplay. The term $a_{\mathrm{RA}}$ was calibrated to provide the best possible agreement of anchovy distribution with the available observed data. Randomness ( $\left.R_{x}, R_{y}\right)$ was set proportional to fish size ( 0.5 body length $\left.\mathrm{s}^{-1}\right)$ assuming that a bigger fish can have a more active random activity in searching, while the random direction was produced from a uniform distribution. 
The value of $a_{\mathrm{RA}}$ was initially set to 0.8 , considering that individuals are mainly driven by food conditions during the winter period. However, it was redefined based on the information that spawning is closely related to the onset of thermocline formation (Planque et al., 2007). This formation was quantified in the model by calculating the temperature difference between the upper $(0-10 \mathrm{~m})$ and lower layers (30-100m) at the current position of each particle. A threshold of $1.2^{\circ} \mathrm{C}$ was imposed to trigger the dominance of SST gradient, which implied a switch of $a_{\mathrm{RA}}$ from 0.8 to 0.3 .

Despite the random component of fish movement, the GAS approach did not prevent in several cases the direct movement and local wandering of particles in optimal grid cells. As a result, the model generated unrealistic patchy patterns. Since a further increase of the randomness would produce high fish swimming velocities, a distinction on the daily swimming behavior was included following the idea of Kirby et al. (2003). Thus, the aforementioned cues were applied for a $12 \mathrm{~h}$ period. The rest half day was considered as a cruising period where individuals were moving exclusively randomly ( $D_{x}=D_{y}=0$ ). This assumption was considered acceptable under the rationale that fish does not search for better conditions in the whole day in the horizontal since it exhibits also vertical movements.

\section{Kinesis algorithm}

For comparison, we tested an alternative approach following the concept of kinesis (Okunishi et al., 2012b; Rose et al., 2015). Contrary to the GAS algorithm, the kinesis behavior considers that individual's response depends upon a habitat index which is defined on the current fish location (Humston et al., 2000). Hence, individuals are able to compare the habitat quality between the current and previous time steps and consequently maintain their fish swimming direction if conditions were improving; otherwise a random search prevails.

The habitat index $(H)$, is defined as the weighted geometric mean of zooplankton biomass $(\mathrm{Z})$ (interpolated horizontally and averaged vertically within 0-40m) and sea surface temperature(SST),

$$
H=\mathrm{Z}^{a_{\mathrm{KIN}}} \mathrm{SSST}^{1-a_{\mathrm{KIN}}}, 0<a_{\mathrm{KIN}}<1
$$


to estimate the habitat condition of anchovy at its current position. The parameter $a_{\mathrm{KIN}}$ was tuned to weight the interaction between $\mathrm{Z}$ and SST (for $a=1 / 2$, we get the standard geometric mean). $a_{\mathrm{KIN}}$ received initially the value 0.7 and after the increased impact of SST, it switched to 0.2. The temperature threshold for performing the switch was set to $0.7^{\circ} \mathrm{C}$.

Practically, the kinesis algorithm was implemented daily for each individual as follows. At the initial time step $k=1$ of a new day, we calculate the habitat index $\left(H_{1}\right)$ at the current fish position and we assume a random search. This random movement defines a direction $\left(G_{x_{1}}, G_{y_{1}}\right)$ such that $R_{x_{1}}=F_{\mathrm{SS}} \rtimes G_{x_{1}}, R_{y_{1}}=F_{\mathrm{SS}} G_{y_{1}}$, whilst $D_{x_{1}}=D_{y_{1}}=0$. Through the Eq. (1), the fish position is then updated. For $k \geq 2$, we recalculate the habitat index $H_{k}$ and we check whether the fish moved to a better habitat i.e. $H_{k}>H_{k-1}$. If this is true, then the new directions $\left(D_{x_{k}}, D_{y_{k}}\right)$ are set $D_{x_{k}}=R_{x_{k-1}}, D_{y_{k}}=R_{y_{k-1}}$ and $R_{x_{k}}=R_{y_{k}}=0$ for the rest of the day. This implies that fish maintains its previous direction. Otherwise, fish continues to ambulate exclusively randomly ( $R_{x_{k}}=F_{S S} \times G_{x_{k}}, R_{y_{k}}=F_{S S} \times G_{y_{k}}$ ) until it finds a better condition. Fish is slowing down ( $F_{\mathrm{SS}}$ was halved) when it is found in areas with high food availability, i.e. when the input energy to the organism ( $f$ ) for food concentration (X) and half saturation ( $\mathrm{K}): f=\frac{\mathrm{X}}{\mathrm{X}+\mathrm{K}}$ (Huret et al., submitted) becomes very high $(f>0.98)$.

\subsection{Design of simulations}

\subsubsection{Reference simulation}

The reference simulation was run from 1-February to 15-June using the attributes of Sim0 (Table 1). The time step was set $\Delta t=3$ hours. 10000 individuals were initially spread within a grid of $35 \times 30$ cells (16km resolution, Fig. 1) following the probabilistic distribution of anchovy presence by length during autumn observations (Petitgas et al., 2011). The initial length of particles was varied within the length range $13-16 \mathrm{~cm}$ following length-at-age-data of mature age-1+ data. The initial values of energy in reserves $(E=118000 \mathrm{~J})$ and in reproduction buffer $(R=62840 \mathrm{~J})$ were extracted from the calibrated sim- 
ulation of Huret et al. (submitted). Initial weight was calculated using the function which converts the energy of structure, reserves and gametes into mass (Huret et al. submitted).

Initial distribution

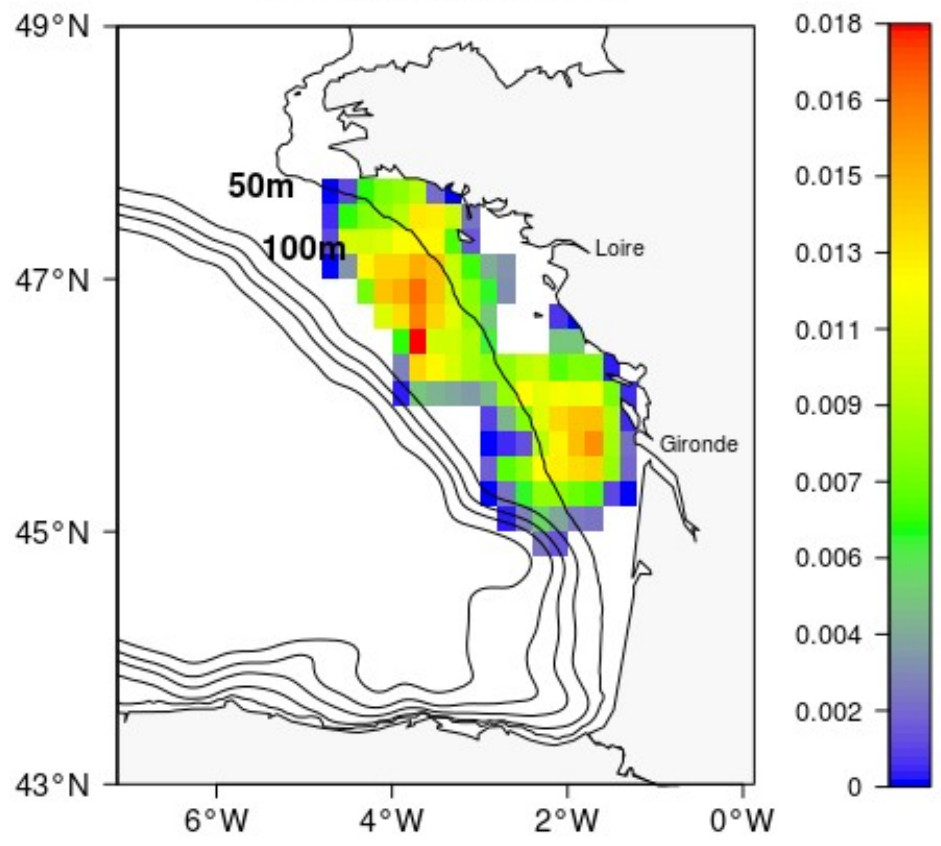

Fig. 1. Initial distribution (in probabilities of presence) of individuals based on autumn observations.

For clarification, we mention that the environmental forcing and the corresponding cues were defined by the horizontal resolution of ECO-MARS (i.e., 4km), while the initial distribution and the model results were analyzed on 16km resolution. Additionally, the natural (other than starvation) and fishing mortality rates were not considered since we do not intend to set a predictive model of population dynamics, but we mainly focus on representing the migration routes.

\subsubsection{Experiment runs}

During the implementation of a fish movement model, several assumptions can affect its performance, including time step (Humston et al., 2000), initial location of individuals (Humston et al., 2004), type of movement (Watkins and Rose, 2012), adopted cues (Okunishi et al., 2012b; Xu et al., 2013) and starting date (Tu et al., 2012). For the purpose of detecting the effect of model's components, we performed ten additional simulations and compare them with the reference run. The attributes of the experiments are listed in Table 1. 
Sim1 was performed using the kinesis algorithm described in 2.3.1. In Sim2 (Sim3), the time step was set to one (five) hours, respectively. A variation on the number of particles to 5000 and 50000 was examined by simulations Sim4 and Sim5. A shift of the starting date one month earlier (January) compare to Sim0 was considered in Sim6, while in Sim7 a uniform initial release of particles was adopted over the northern part of the continental self $(<200 \mathrm{~m})$ between $45.25^{\circ} \mathrm{N}$ and $47.5^{\circ} \mathrm{N}$. Using as a single cue the zooplankton fields in Sim8, we explored the impact of food in the movement process. Sim9 was performed using exclusively SST as driver of the fish behavior. Finally, in Sim10 we tested the bioenergetic cue discussed in section 2.3.1.

\begin{tabular}{ccccccc}
\hline Simulations & $\begin{array}{c}\text { Time } \\
\text { step }\end{array}$ & $\begin{array}{c}\text { Movement } \\
\text { type }\end{array}$ & $\begin{array}{c}\text { Initial } \\
\text { location }\end{array}$ & $\begin{array}{c}\text { Initial } \\
\text { month }\end{array}$ & \# of particles & Cues \\
\hline Sim0 & 3h & $\begin{array}{c}\text { GAS } \\
\text { Sim1 }\end{array}$ & Habitat & February & 10000 & Food (0-40m)+SST \\
Sim2 & 1h & & & & & \\
Sim3 & $5 \mathrm{~h}$ & & & & & \\
Sim4 & & & & & 5000 & \\
Sim5 & & & & January & & \\
Sim6 & & & Random & & & \\
Sim7 & & & & & & Food (0-40m) \\
Sim8 & & & & & & SST \\
Sim9 & & & & & & Bioenergetics \\
Sim10 & & & & & \\
\hline
\end{tabular}

Table 1. Attributes of simulations. Sim0 is considered as the reference run. The empty cells indicate the same assumptions as in base-case simulation Sim0.

\subsubsection{Model skill assessment and spatial indices}

The effectiveness of the model at reproducing aggregations similar to summer observations was examined by plotting the anchovy distribution at the end of the simulation (15 June). To do that, we considered a grid of $35 \times 30$ cells (16km resolution) on the model domain. The number of individuals in each cell was counted and divided by the total number of particles, so that fish distribution was converted to a continuous concentration field used in the calculation of spatial indices. Similar probability data were derived from Petitgas et al. (2011) and interpolated on the same grid.

In terms of bioenergetics outputs, spatial maps of anchovy's weight and length change between the starting and ending time of the run were computed to identify areas which overall supported better fish growth. Also, the change in fish energy was mapped to identify areas supporting better fish condition, 
as an additional indicator since energy is not fully correlated to weight depending on the reserve accumulation and water content (Huret et al., submitted). Simulated spawning habitats were obtained by summing spatially over the grid cells the energy of all eggs released by adults.

A Taylor diagram (Taylor, 2001) was used to validate the model's skill and detect the differences between the experiment runs. It provides a concise statistical summary of how closely model outputs match with observations and it is also suitable to track changes in performance of a model as it is modified. Simulated and observed spatial fields were compared using as metrics the correlation coefficient (R), the centered root-mean-square difference (RMS) and their standard deviations (SDs) normalized to the observations’ SD. Good performance of Taylor diagram implies high value for R (close to 1), small RMS (close to 0 ) and SD close to 1.

In addition, the following spatial indices were used to compare the fish distribution maps between the experiment runs: the longitude and latitude of Center of Gravity (CG), the inertia, the global index of collocation (GIC), and the ratio of the positive to the spreading area (PA/SA) (Table 2). The inertia informs on the dispersion of distribution around its CG and in particular, Principal Component Analysis applied on particle positions defines the major axes of orientation and elongation of the distribution. The GIC informs on the degree of overlap between two distributions and varies between 0 (no overlap) and 1 (complete overlap). Here, the GIC compared simulation runs to observations. The spreading area (SA) informs on the degree of aggregation: the more aggregated the population the smaller its SA and for an evenly distributed population SA is equal to PA. More details on these indices can be found in Woillez et al. (2007).

\begin{tabular}{ll}
\hline \multicolumn{1}{c}{ Metrics } & \multicolumn{1}{c}{ Description } \\
\hline $\begin{array}{l}\text { Center of Gravity (CG) } \\
\text { Inertia (I) }\end{array}$ & $\begin{array}{l}\text { Mean location of the distribution (lon, lat) } \\
\text { Dlobal index of } \quad \text { collocation }\end{array}$ \\
$\begin{array}{l}\text { (GIC) } \\
\text { Positive area (PA) }\end{array}$ & $\begin{array}{l}\text { It measures how geographically distinct two } \\
\text { distributions are (value between 0 and 1) } \\
\text { Sum of area units containing at least one particle } \\
\text { (square kms) } \\
\text { Spreading area (SA) }\end{array}$ \\
& $\begin{array}{l}\text { Measure of how the distribution of fish particles } \\
\text { is aggregated (square kms) }\end{array}$ \\
\hline
\end{tabular}

Table 2. List of spatial indices used to summarize the spatial distributions of particles (Woillez et al., 2007).

\section{Results}




\subsection{Reference simulation}

The snapshot of simulated anchovy distribution at the end of the simulation is compared to observed distribution map in Fig. 2. Higher fish aggregation was noticed below $45.5^{\circ} \mathrm{N}$ for both model and data. Given that initially $9 \%$ of individuals were located southerly at $45.5^{\circ} \mathrm{N}$, the percentage was increased after all to $56.3 \%$. Contrary to in situ data, the reference simulation did not create high concentrations inshore $(<50 \mathrm{~m})$ in front of the Gironde river (Fig. 2a). Instead, a number of individuals moved further offshore between $45.5-46^{\circ} \mathrm{N}$ occupying areas with bathymetry between 50-100m.
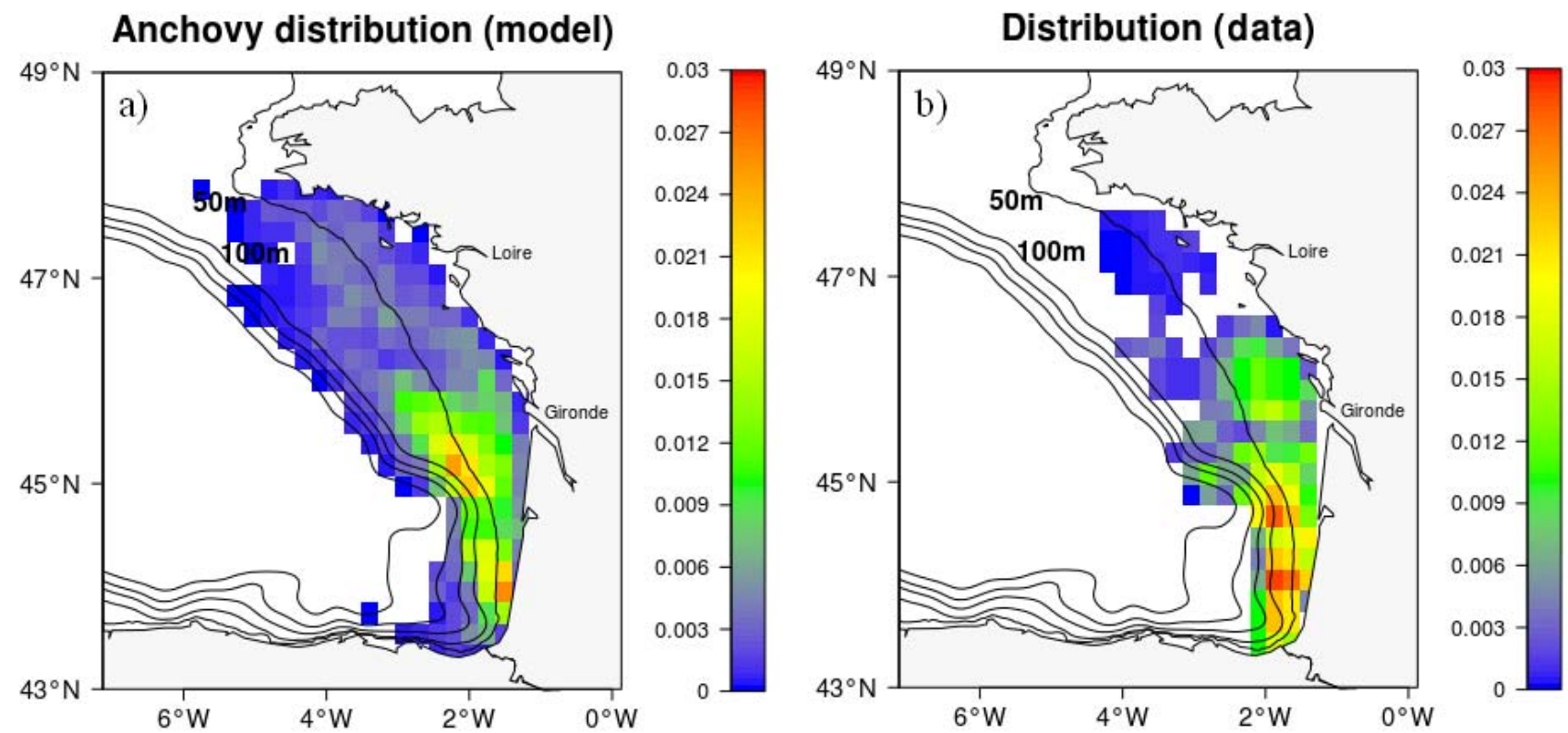

Fig. 2. a) Simulated map of anchovy distribution against b) observations calculated as probability of presence.

The daily overlap of simulated and observed distributions through the GIC index is shown in Fig. 3a. GIC starts at 0.38 and gradually increases to 0.91, indicating a good overlap between the two spatial patterns. The average movement route of particles was extracted by plotting the geographic positions (lon, lat) of CGs (dashed line of Fig. 3b). It can be summarized as follows: starting from $\left(2.8^{\circ} \mathrm{W}\right.$, $46.3^{\circ} \mathrm{N}$ ) the CG performs a downward shift and at the same time towards inshore from February till early April. Afterwards, under the continuous effect of food and the increasing effect of SST gradient, the CG starts to move slightly offshore and concurrently more actively to the south. The principal axes of inertia of the particle distribution (Fig. 3b) at the end of the simulation (black axis) show an alongshelf orientation with the final CG located in $\left(2.2^{\circ} \mathrm{W}, 45.4^{\circ} \mathrm{N}\right)$. Grey axes show the initial inertia while 
the blue axis corresponds to the inertia of the data.
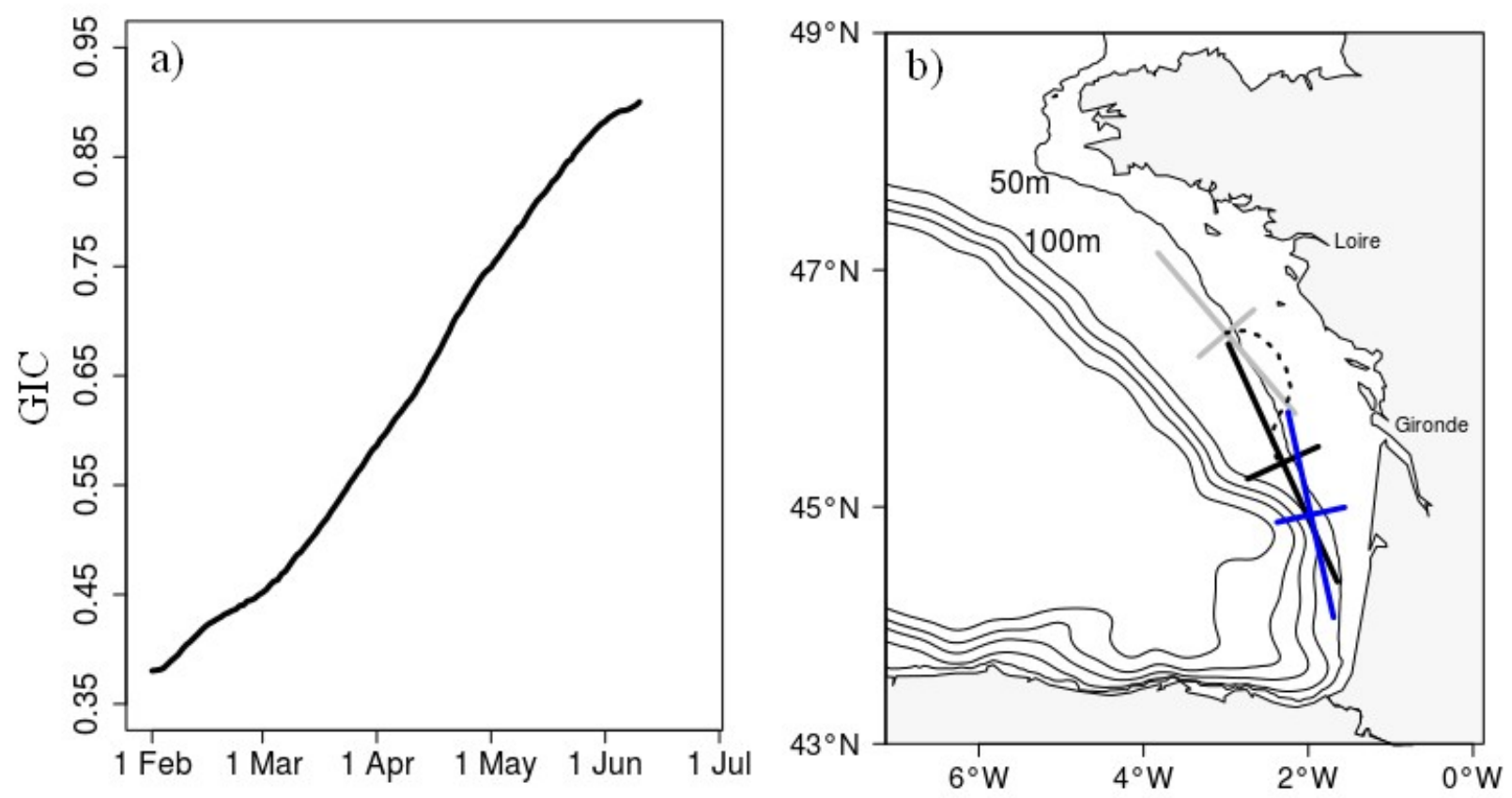

Fig. 3. a) Time series of GIC index. b) The dashed line represents the trajectory of the CGs. Crosses show the principal axes of inertia around the CGs, which are positioned at the mid-point of the axes.

The total changes of anchovy's bioenergetics as regards to length, weight, fish energy and cumulated energy spend on reproduction are mapped in Fig. 4. Over the whole bay, the mean weight change was 9.4\% (Fig. 4a), the mean length change 6.6\% (Fig. 4b) and fish energy change 8.3\% (Fig. 4c). Drawing a latitudinal limit at $46^{\circ} \mathrm{N}$, individual fish that ended up south of $46^{\circ} \mathrm{N}$ showed changes in mean weight change of $11.1 \%$, mean length change of $6.9 \%$ and mean energy of $11.2 \%$. In contrast, the corresponding values for particles remaining north of $46^{\circ} \mathrm{N}$ were $4 \%, 5.5 \%$ and $-0.7 \%$. The weight change was low mainly for individuals remaining north of $46^{\circ} \mathrm{N}$ and offshore. Interestingly, the change in fish energy was negative for the majority of individuals which remained north of $46^{\circ} \mathrm{N}$, meaning that they grew at the cost of reserve diminution. Concerning the spatial pattern of the cumulative energy of released eggs (Fig. 4d), higher values are obtained mostly in cells below $46^{\circ} \mathrm{N}$. However, northerly of $46^{\circ} \mathrm{N}$, increased energy invested for reproduction is noticed mainly in coastal areas with bottom depth lower than 50m (Fig. 4d). 

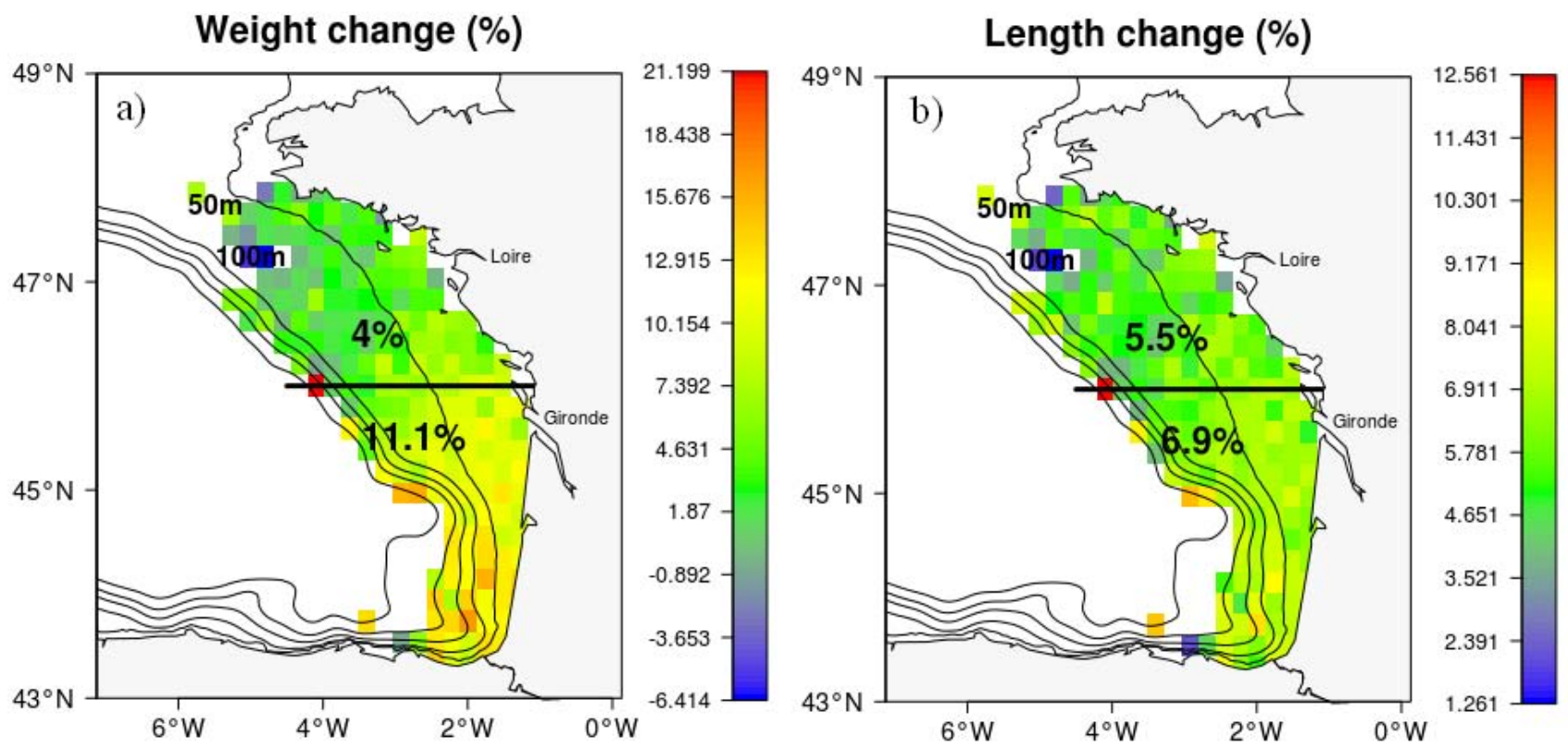

Fish energy change (\%)
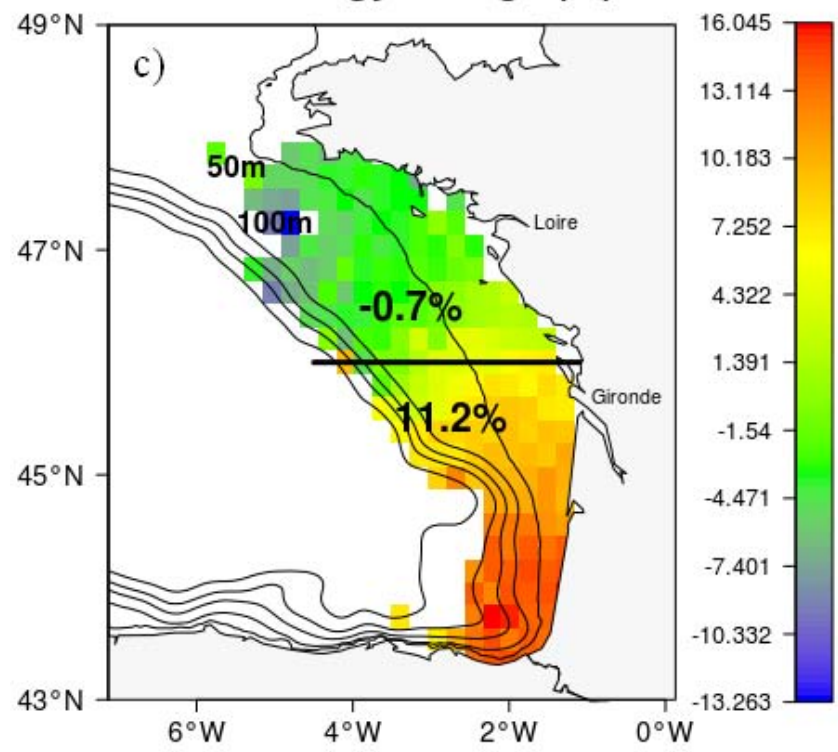

Energy of released eggs $(\mathrm{KJ})$

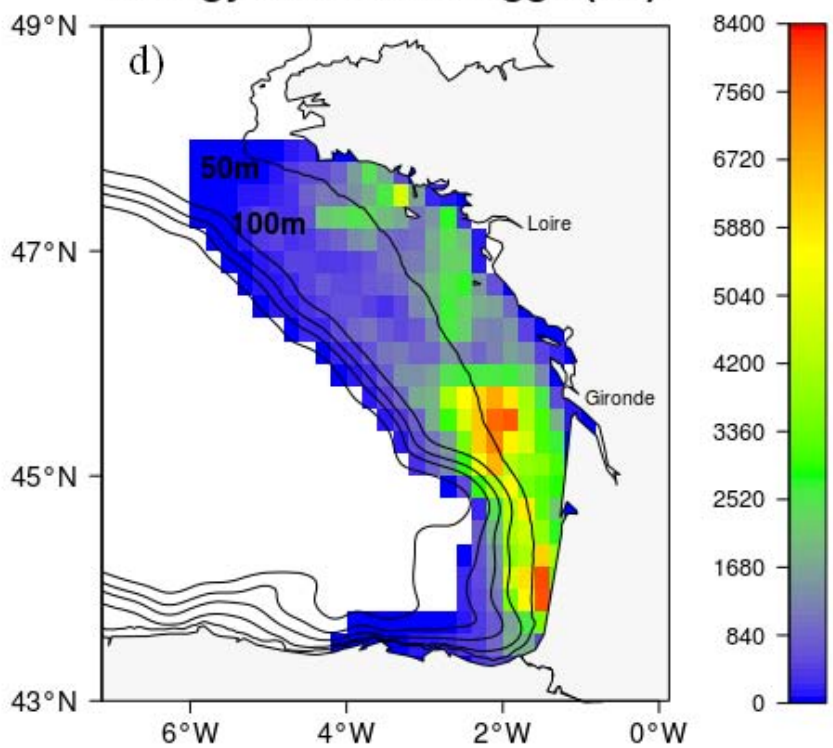

Fig. 4. Spatial characteristics of the bioenergetics integrated over the simulation period: a) weight change, b) length change, c) fish energy change and d) cumulative energy of released eggs.

\subsection{Experiments}

Pattern statistics for the eleven simulations of Table 1 were computed and the position of each point appearing on the Taylor diagram (Fig. 5) quantified how closely simulated distributions (Fig. 6) matched with observations (Fig. 2b). All experiment runs displayed higher aggregations below $46^{\circ} \mathrm{N}$ (Fig. 5) but their performance showed differentiations. The reference run (point 0 ) indicated a correlation coef- 
ficient $\mathrm{R}=0.55$, square root error $\mathrm{RMS}=0.87$ and standard deviation, $\mathrm{SD}=0.81$. The kinesis algorithm (point 1 ) has a slightly smaller correlation coefficient $(\mathrm{R}=0.52)$ and smaller RMS (0.85) as compared to Sim0 but it simulates the amplitude of the variations less well resulting with a lower SD=0.6. Of the poorer performing models, Sim2 (point 2) displayed a low pattern correlation $(\mathrm{R}=0.23)$ and high error (RMS=1.36). The increase of time step (point 3) increased the correlation coefficient to 0.57 but decreased significantly the standard deviation $(S D=0.43)$. The variation on the number of particles (points 4,5) and the random initialization (point 7) did not significantly change the Taylor metrics while the shift of initial date (point 6) contributed to a slight increase of correlation coefficient $(\mathrm{R}=0.59)$ and a slight decrease of RMS=0.82, compared to reference run (Sim0). Sim8 (point 8) implied a very low correlation $\mathrm{R}=0.15$ and high error RMS=1.12. Similarly, the SST cue alone (point 9) had also low correlation $\mathrm{R}=0.4$ and high error (RMS=1.62). Finally, the bioenergetics cue alone (point 10) showed also a low performance with $\mathrm{R}=0.21$ and high error, $\mathrm{RMS}=1.18$.

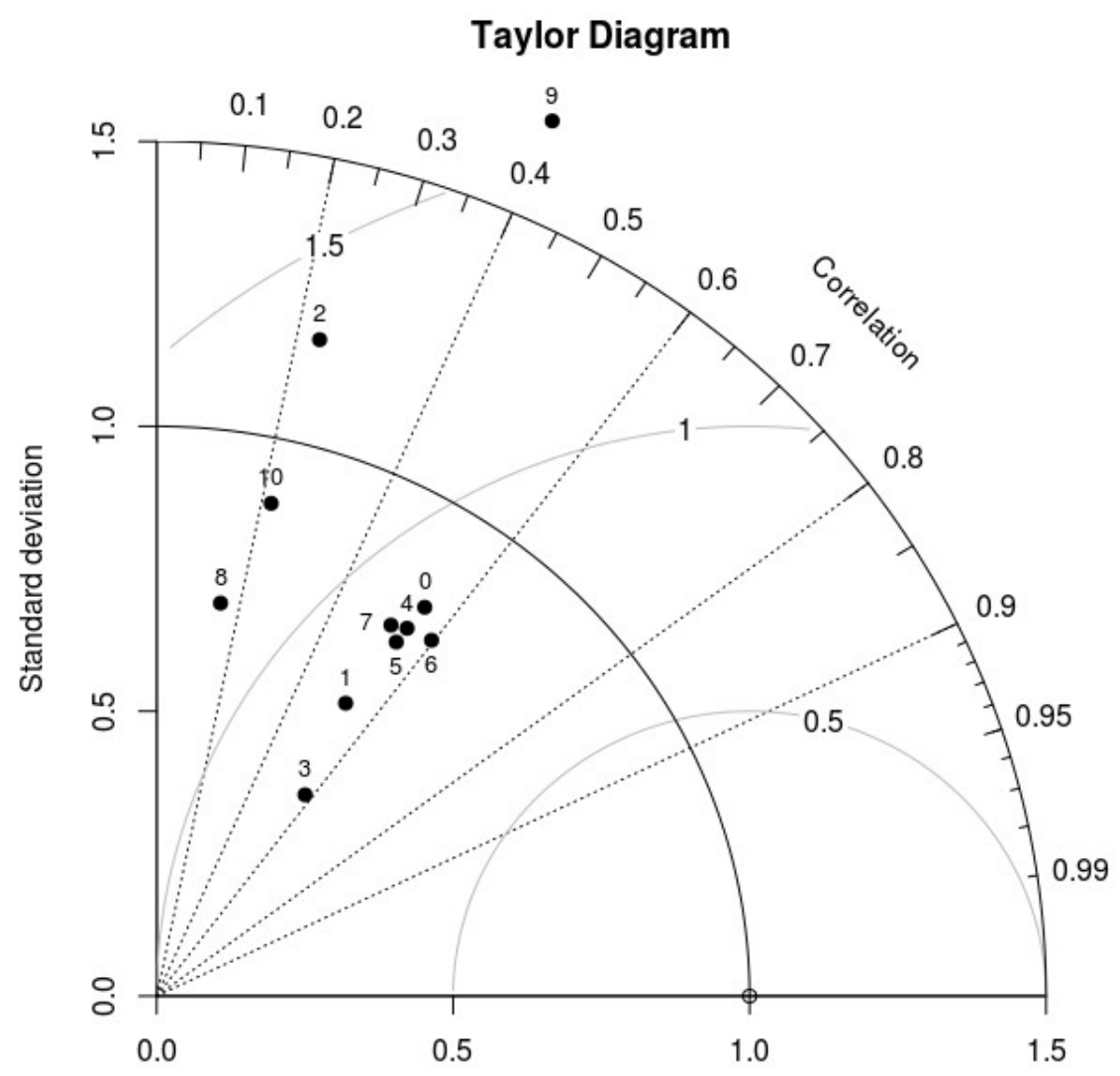

Fig. 5. Taylor diagram comparing the simulated distributions Sim0 to Sim10 against observations. Simulation runs are detailed in Table 1. 

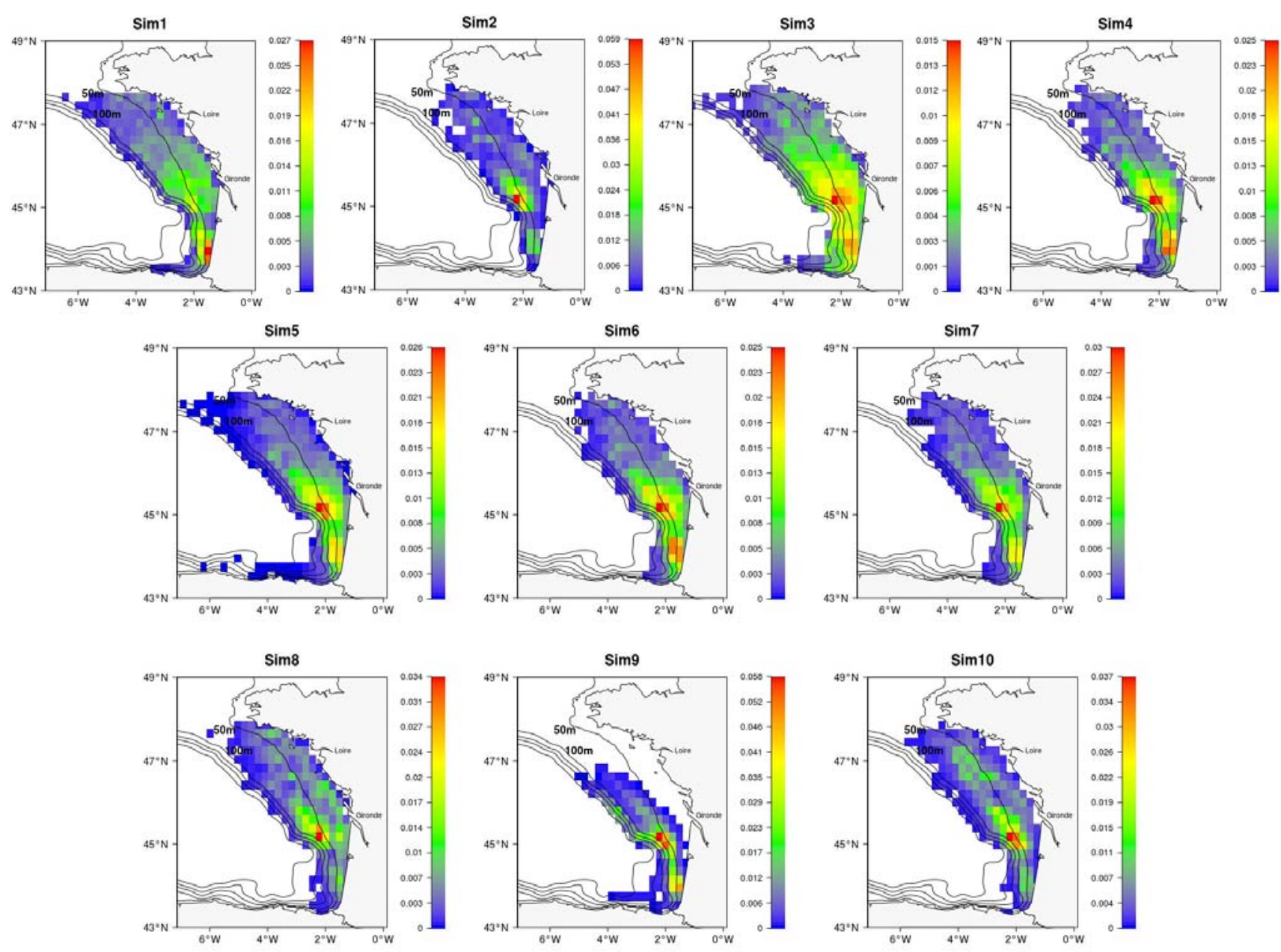

Fig. 6. Anchovy distributions maps derived from experiment runs (Table 1).

Sensitivity analysis on the model time step demonstrated that one hour resolution (Sim2) caused a decrease of both GIC (0.74) and SA/PA (0.42) in comparison to Sim0 (Fig. 7). On the other hand, the increase of time step to five hours (Sim3) decreased GIC (0.84) and increased significantly the ratio SA/PA making the anchovy distribution more aggregated. Simulations Sim4 to Sim7 did not make the GIC vary significantly, while Sim8 and Sim10 had low GIC ( $\approx 0.70)$. The aggregation in the simulated spatial patterns (SA/PA) was not notably affected by the shifting of initial date (Sim6) and the random initialization (Sim7), whereas the decrease (Sim4) and increase (Sim5) on the number of particles caused a slightly higher (lower) dispersion, respectively. Sim9 had high GIC value (0.95) but at the same time the lowest value of spreading (SA/PA=0.33). Sim10 showed a low $\mathrm{GIC}=0.7$ and a spread similar to that of Sim0. 

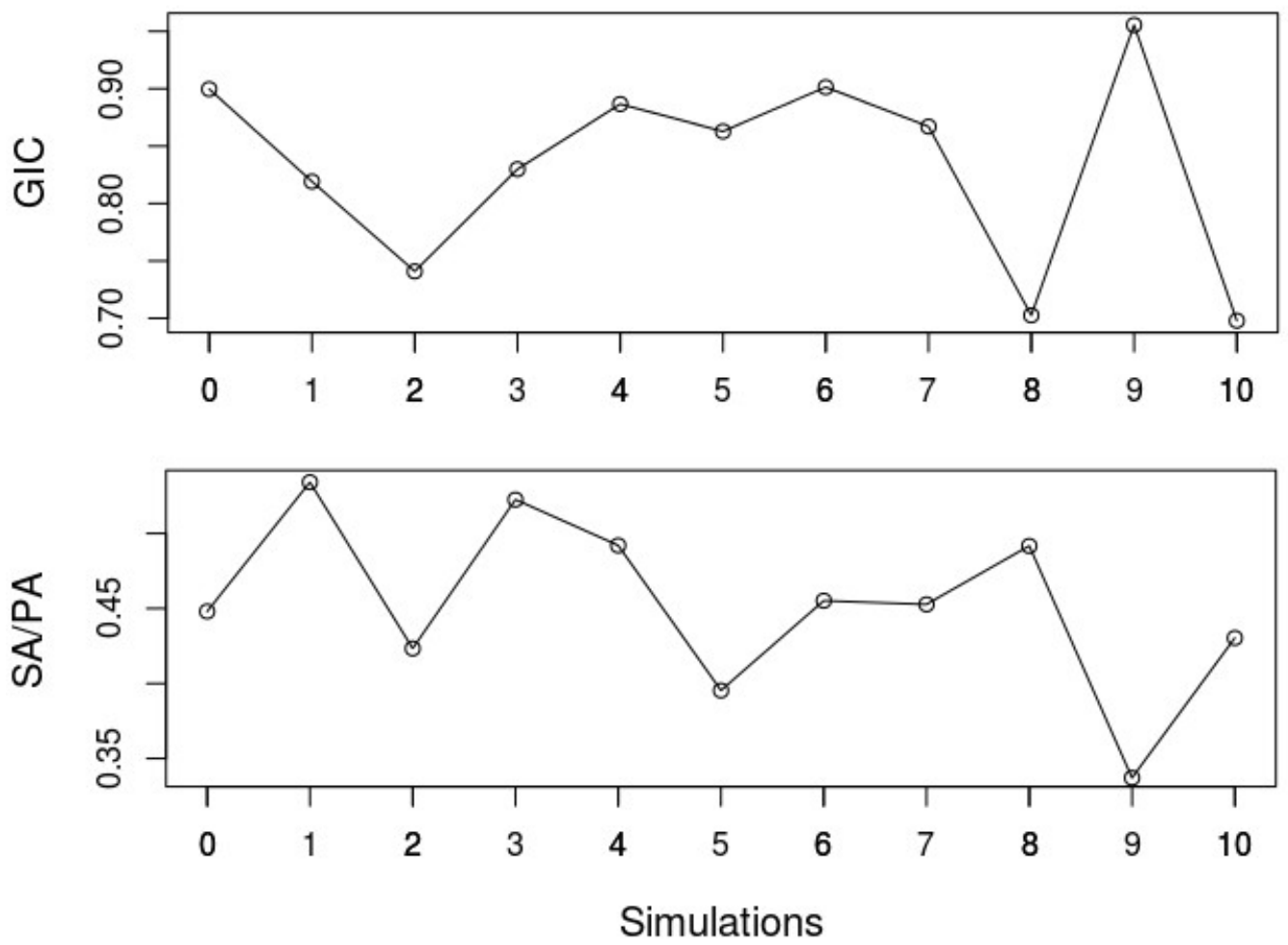

Fig. 7. Plot of GIC and SA/PA indices for all simulations. Indices are detailed in Table 2.

Fig. 8 provides a comparison of the variation of latitude of CGs for all runs. Visually, the general pattern for simulations Sim0 to Sim8 is characterized by a gradual descent of latitude, which becomes more intense from early April until the middle of May following the gradual increase of temperature and zooplankton (Fig. 9). The kinesis algorithm (Sim1) showed a smoother pattern compared to the GAS algorithm, which resulted in moderate downward motion of individuals, especially after May. One-hour time step (Sim2) and food cue (Sim8) were ineffective to induce a notable latitudinal displacement, while SST cue (Sim9) displayed an active latitudinal movement which started in February and continued till the end of the simulation. Finally, bioenergetics cue (Sim10) displayed at the end a CG latitude similar to Sim2, revealing, however, a different movement pattern. Interestingly, contrary to other simulations, the southward shift was more direct during May. 


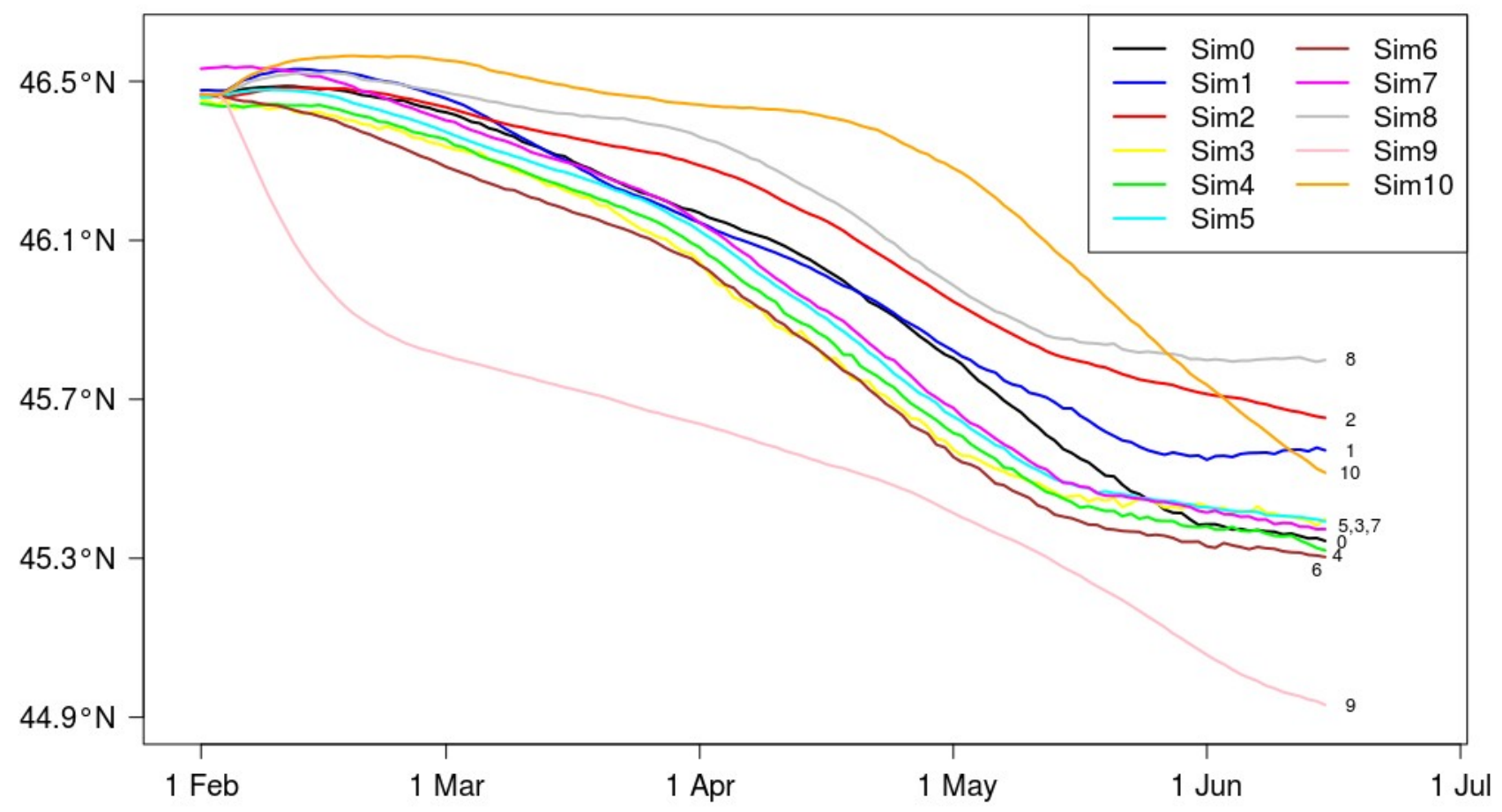

Fig. 8. Plots of latitudes of the CGs. Runs are detailed in Table 1. 

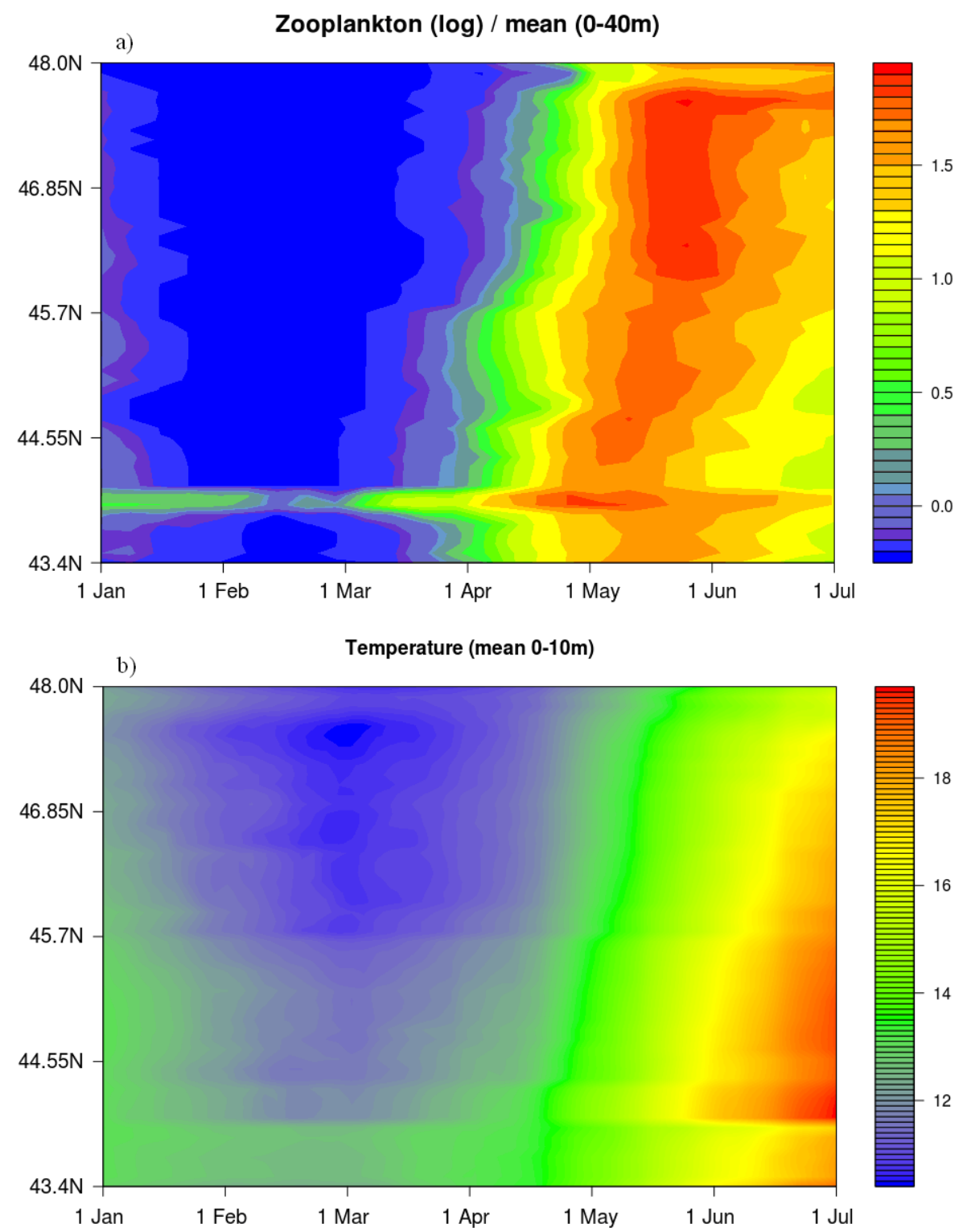

Fig. 9. a) Mean zooplankton ( $\mathrm{mgC} / \mathrm{m}^{3}$ ) over $0-40 \mathrm{~m}$ and b) mean temperature $\left({ }^{\circ} \mathrm{C}\right.$ ) over $0-10 \mathrm{~m}$ (lower) calculated along the transect of $100 \mathrm{~m}$ from south to north.

\section{Discussion}

\subsection{Model evaluation}

The reference run proposed that gradient area search with zooplankton and SST as cues was the most appropriate mechanism to induce north to south mobility of individuals and recreate successfully the observed anchovy distribution. Moreover, it demonstrated that the southward migration becomes more 
direct from early April to mid-May (Fig. 8) following properly ECO-MARS3D forcing environment, which predicts an increase of both temperature and plankton dynamics in the south of the Bay in spring (Figs. 9 and 10).
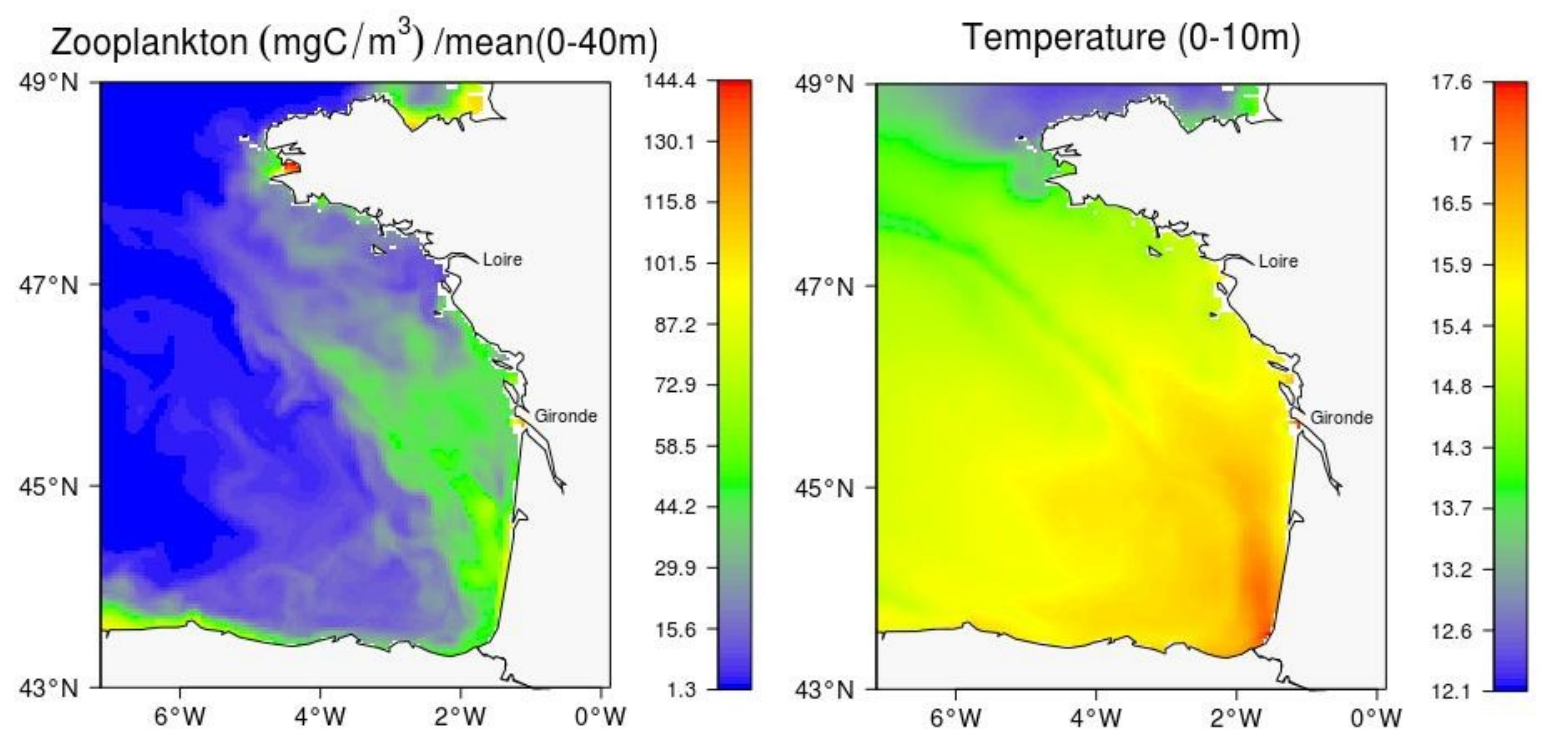

Fig. 10. Snapshots of zooplankton and temperature fields during middle May.

The interplay between zooplankton and SST was balanced through the parameter $a_{\mathrm{RA}}$ for GAS algorithm and $a_{\text {KIN }}$ for the kinesis model. We point out that although these parameters were not possible to be estimated from any data, they parameterized an important process in the model. Their main contribution was to trigger the "SST gradient dominance hypothesis" through the Eqs. (4) and (5). Taylor results (point 0, Fig. 5) showed that this switch and its timing may be indeed important to finalize successfully the geographical shift of the individuals. In terms of their sensitivity, small changes on their values did not severely affect the model's performance. Values between 0.7-0.9 for both $a_{\mathrm{RA}}$ and $a_{\mathrm{KIN}}$ during the first phase of locomotion were sufficient. After the switch of fish behavior from food driven to more SST driven, the model was able to work efficiently when $a_{\mathrm{RA}}$ took values between 0.25-0.35 and $a_{\mathrm{KIN}}$ between 0.2-0.3. Similar concept was adopted Tu et al. (2012) who assumed a stepwise swimming scheme where fish was switching its stimuli from current to temperature when sensing the optimal temperature for spawning. 
Our use of GAS behavior to actualize the reference run was motivated by the spring environmental fields which are characterized by a progressively established north to the south gradient (Fig. 10). This choice is consistent with the recommendation of Watkins and Rose (2013) who suggested that gradient based approaches seem more appropriate to simulate a population that strongly aggregates in response to gradually changing cues. However, consideration of other approaches for representing behavioral movement is equally important given that variations in spatial patterns and growth dynamics can be found due to the way fish perceive and respond to its living conditions (Humston et al., 2004; Okunishi et al., 2012b; Watkins and Rose, 2013). Hence, we implemented the kinesis behavior as an alternative mechanism to induce anchovy’s spawning movement. In section 4.3, we discuss its performance and its differences with GAS.

\subsection{Ecological significance of the spawning migration}

The coupling of the growth model with the movement process justified that the individuals who shifted to the southern part of the bay were benefited in terms of fish bioenergetics as compared to those remaining in the north (Fig. 4). Particles that finally ended below $46^{\circ} \mathrm{N}$, showed a better growth based on their weight and length (Fig 4a, 4b). Even more contrasted is the difference in fish condition based on their energy content (Fig 4c). Individuals remaining in the north had a negative energy balance between winter and late spring, while those having migrated south were able to replenish their energy more rapidly after the winter, as showed beneficial both in terms of growth and reproduction.

Concerning the simulated spawning grounds, we notice that they are consistent with the spatial distribution patterns southern of $46^{\circ} \mathrm{N}$ (Figs. 2a, 4d). For the individuals that aggregated in the northern part of the bay, those showing higher egg production were located in coastal waters (Fig. 4d). The simulated spawning areas are in agreement with observed egg distribution maps (Motos et al., 1996; Bellier et al., 2007). Our modelling results then suggest that this late-spring spawning spatial pattern, with higher fecundity in the south, is a result of the general southward movement of the population, as well as the associated better bioenergetics conditions as compared to the individuals remaining in the north. For those latter ones, remaining close to the coast is a better than spreading over the shelf.

The positive effect of fish migration on growth and population dynamics of a stock has been also ascertained in other model studies. For example, Okunishi et al. (2012b) demonstrated that in the 
western Pacific ecosystem, the migration of juvenile Japanese sardines exposed them to optimal temperatures and high chlorophyll concentrations for growth, while the average spatial distribution of Peruvian anchovy implied that the movement of the population to relatively cool waters and high productivity areas supported better growth conditions and high survival rates (Xu et al., 2013).

\subsection{Comparison of experiments}

Comparing kinesis with GAS scheme, we note that kinesis resulted in lower simulation skills (Fig. 5, point 1), while it did not demonstrate a significant southern shift of individuals (Fig. 8, Sim1). In terms of spatial indices, kinesis scheme displayed fish distribution with lower value of GIC and higher spreading than GAS (Fig. 7). It seems that the advantage of GAS to allow fish detecting habitat quality in the surrounding environment had an edge to induce a southward migration that recreated better the observed anchovy distribution (Fig. 6, Sim0). Representing fish movement following the restricted area search scheme has been proven useful also in other studies like in Xu et al. (2013) and Railsback et al. (1999) who assumed that individuals can evaluate growth rates in the neighborhood cells and move towards the cell which provides the maximum fitness.

Despite the lower efficiency of the kinesis algorithm, we argue that it cannot be rejected as an alternative movement strategy. Identification of other meaningful biological stimuli which can determine when a fish leaves or remains its current location could perhaps improve its performance. We recall that generally, kinesis has been proposed as a more useful choice when simulating a species that explores its environment with a wandering behavior and not by searching for local optima (Humston et al., 2004). As a result, final fish distributions are characterized by more scattered patterns (Watkins and Rose, 2013). For instance, Okunishi et al. (2012) predicted that kinesis was more accurate than the fitness search behavior, to reproduce the observed northward migration of juvenile sardine in the western Pacific.

Evaluating the effect of computational and behavioral assumptions is indispensable to discern the capabilities and the limits of the model (Humston et al., 2004). Watkins and Rose (2014) illustrated that the minimum fish swimming speed was not slow enough to maintain model individuals near highquality habitats under longer time steps, while the number of particles reaching the spawning grounds in the coastal waters of Taiwan was decreased when there was a delay of one month on the starting date 
(Tu et al., 2012). For this reason, we performed a series of sensitivity tests and compare them using spatial indices and CGs latitudes. Sensitivity results demonstrated that individuals reflect similar migration patterns (Fig. 8) but they exhibit differentiations in their final distribution. Thus, Taylor diagram results (Fig. 5) and GIC metric (Fig. 7) showed that the simulated spatial patterns did not significantly change due to the variations on particle number (Sim4, Sim5), the shift of initial date (Sim6) and the random initialization (Sim7), while more spreading of the population (SA/PA) occurred especially when we increased the number of particles (Fig. 7b, Sim4). Regarding the time step and the adopted cues, they affected drastically the model's performance. Both the decrease and increase of time step by two hours (Fig. 5, Sim2 and Sim3) worsen the model's performance. When the food used a cue (Fig. 6, Sim8), its poor performance indicated that it cannot be the only factor controlling spawning movement. Under SST scenario, many particles moved offshore (Fig.6, Sim9), whereas a significant proportion ended in the south. Despite its high value of GIC (Fig 7a), it was documented as the simulation with the highest RMS error, implying that SST cannot be the exclusive driver of anchovy movement.

\subsection{Model limitations}

The reference run was not very efficient to realize a massive "large scale" displacement of particles south of $46^{\circ} \mathrm{N}$ whose initial positions were on the upper part of BoB. More particularly, 23.3\% of the particles that had initial latitude positions above $46^{\circ} \mathrm{N}$ were moved finally below $45^{\circ} \mathrm{N}$, while $11 \%$ of particles who were initially above $47^{\circ} \mathrm{N}$, they were finally found within the continental shelf southerly of $45^{\circ} \mathrm{N}$ at the end of the simulation (Fig. 2a). Additionally, the simulated distribution predicted increased concentration offshore between $45-46^{\circ} \mathrm{N}$ which was not compatible with observations. This mismatch can be explained by the fact that during May-June except from the latitudinal gradient of SST, there was also an inshore to offshore gradient (Fig. 10). Other mechanisms not included, for example the energetic cost of movement or evolutionary selection of spawning habitats could probably prevent this misplacement.

Due to the absence of empirical support of behavioral assumptions (Humston et al., 2004), the imposition of rules and the testing of cues are the common ways to determine when individuals depart

their current locations and how they select destinations when implementing a fish IBM movement model (Railsback et al., 1999). In Okunishi et al. (2012b), chlorophyll-a concentration, SST and sea- 
surface velocity were used as external forces to simulate growth and migration of Japanese sardine in the western North Pacific, while tuna's migration in the Gulf of Maine was driven by SST maps (Humston et al., 2000). Temperature and current at a given depth were adopted as cues to explain the spawning migration routes of Icelandic capelin stock (Barbaro et al., 2009). In this study, we used simplified but meaningful cues as potential mechanisms to drive anchovy to spawning habitats. Thus, average values of zooplankton and temperature over the water column as well as SST were used as forcing inputs. However, defining more dynamic ways or simulating vertical fish movement could provide more realistic explanations about the effects of vertical environmental variability on the movement process. This was especially evident for the bioenergetics cue (Fig 5, Sim10) which predicted a latitudinal shift of the population (Fig. 8, Sim10) who was poorly compatible with observed distribution (Fig 5, point 10).

All the simulations were realized under climatological forcing conditions. Additional runs that will take into account climate and plankton interannual variability will further enlighten the relationship between fish behavior and environment. Contrary to other studies, we did not adopt an optimum temperature to trigger (Tu et al., 2012) or slow down (Humston et al., 2000; Okunishi et al., 2012b) the impact of temperature, since there was no empirical study that can support an evident value. Including this kind of information in a future study would produce more realistic motions towards preferred environmental conditions, given that high deviations from optimal conditions can limit or delay migration success. Another question that needs further elaboration when modelling spawning movement concerns the motivation of the fish. It would be challenging to explore evolutionary rather than ecological drivers of movement as proposed by Huse and Ellingsen (2008) and Okunishi et al. (2009).

As mentioned in the implementation section, the effect of the mortality was not assessed in our study. Considering the fact that fishing mostly occurs mostly during April to June when Spanish fleet is active in the south of the bay (ICES, 2014), fishing mortality is likely to modulate and play a role in the observed spatial distribution at the end of spring. However, this would need to be investigated on a yearly basis based on the interannual variability of fishing effort. Based on the fact that during our period of observation (decade 2000) fishery was close from 2005 to 2009, we believe that this effect is rather limited.

In summary, we compounded a fish movement-bioenergetics model in order to increase our 
understanding on the underlying mechanisms that define the movement routes of anchovy in the BoB. Our study proposed a potential mechanism for the southward movement success during spring months and confirmed the resulting fish energy gain as an ecological explanation for this migration. Future efforts that will reproduce the late summer feeding migration towards the north of the bay is the next necessary step to complete the annual life cycle of anchovy in the BoB.

Acknowledgments. This research was funded by the project SEAMAN (Spatially resolved Ecosystem Models and their Application to marine MANagement) within the framework of the EU FP7 ERA-NET SEASERA. The authors would like to acknowledge Kenneth A. Rose for his advices on movement technical issues. Special thanks also to Takeshi Okunishi and Shin-Ichi Ito for their assistance on the implementation of the kinesis algorithm. Finally, we thank the two reviewers for their useful comments.

\section{References}

Barbaro, A., Einarsson, B., Birnir, B., Sigurðsson, S., Valdimarsson, H., Pálsson, Ó.K., Sveinbjörnsson, S., Sigurðsson, P. 2009. Modelling and simulations of the migration of pelagic fish. ICES J. Mar. Sci. 66(5), 826-838.

Bellier, E., Planque, B., Petitgas, P., 2007. Historical fluctuations in spawning location of anchovy (Engraulis encrasicolus) and sardine (Sardina pilchardus) in the Bay of Biscay during 1967-73 and 2000-2004. Fish. Oceanogr. 16(1), 1-15.

Checkley, Jr., D.M., Ayon, P., Baumgartner, T.R., Bernal, M., Coetzee, J.C., Emmett, R., GuevaraCarrasco, R., Hutchings, L., Ibaibarriaga, L., Nakata, H., Oozeki, Y., Planque, B., Schweigert, J., Stratoudakis, Y., van der Lingen, C., 2009. Habitats. In: Checkley, D.M., Jr., Alheit, J., Oozeki, Y., Roy, C. (Eds.), Climate Change and Small Pelagic Fish. Cambridge University Press, Cambridge, pp. 12-44.

Chen, C., Tzeng, C., Chiu, T., 2010. Morphological and molecular analyses reveal separations among spatiotemporal populations of anchovy (Engraulis japonicus) in the Southern East China Sea. Zool. Stud. 49(2), 270-282.

Fréon, P., Coetzee, J.C, van der Lingen, C.D., Connell, A.D,. O’Donoghue, S.H, Roberts, M.J., Demarcq, H., Attwood, C.G., Lamberth, S.J., Hutchings, L., 2010. A review and tests of hypotheses about causes of the KwaZulu-Natal sardine run. Afr. J. Mar. Sci. 32(2), 
449-479.

Giannoulaki, M., Schismenou, E., Pyrounaki, M., Tsagarakis, K., 2014. Habitat characterization and migrations. In: Ganias K. (ed), Biology and ecology of sardines and anchovies. CRC Press, Taylor \& Francis Group, pp. 190-242 (Chapter 5).

Huret, M., Sourisseau M., Petitgas P., Struski C., Leger F., Lazure P. 2013. A multi-decadal hindcast of a physical-biogeochemical model and derived oceanographic indices in the Bay of Biscay. J. Mar. Syst., 109, 77-94.

Huret, M., Garnier, V., Grellier, P., Petitgas, P., Sourisseau M., 2015. Calibration of a 3D bioenergetic IBM of anchovy in the Bay of Biscay with seasonal constraint in energy density and spatial distribution. Ecol. Model., Submitted.

Huse, G., Ellingsen, 2008. Capelin migrations and climate change- a modelling analysis. Climatic Change 87, 177-197.

Humston, R., Ault, J.S., Lutcavage, M., Olson, D.B., 2000. Schooling and migration of large pelagic fishes relative to environmental cues. Fish. Oceanogr. 9, 136-146.

Humston, R., Olson, D.B., Ault, J.S., 2004. Behavioral assumptions in models of fish movement and their influence on population dynamics. Trans. Am. Fish. Soc. 133, 1304-1328.

ICES, 2010. Life cycle spatial patterns of small pelagic fish in the Northeast Atlantic. ICES Cooperative Research Report, No. 306.

ICES, 2014. Report of the Working Group on Southern Horse Mackerel, Anchovy and Sardine (WGHANSA).

Ito, S-I., Okunishi, T., Kishi, M.J., Wang, M.,2013. Modelling ecological responses of Pacific saury (Cololabis saira) to future climate change and its uncertainty. ICES J. Mar. Sci. 70(5), 980-990.

Kirby, S., Huse, G., Lehodey P., Hart, P., 2003. An individual-based model for the spatial population dynamics of Pacific skipjack tuna Katsuwonus pelamis: model structure [SKJ-4]. Noumea, New Caledonia: SPC, Secretariat of the Pacific Community. Standing Committee on Tuna and Billfish, Mooloolaba, Queensland, Australia, 9-16 July 2003, 16th. pp. 30.

Kooijman, S.A.L.M., 2010. Dynamic energy budgets theory for metabolic organization, 3rd Edition Cambridge University Press.

Koutsikopoulos, C., Cann, B.Le, 1996. Physical processes and hydrological structures related to the Bay of Biscay anchovy. Sci. Mar. 60(Suppl.2), 9-19.

Lazure, P., Dumas F., 2008. An external-internal mode coupling for a 3D hydrodynamical model for applications at regional scale (MARS). Adv. Water Res, 31(2), 233-250. 
Lehuta, S., Petitgas, P., Mahévas, S., Huret, M., Vermard, Y., Uriarte, A. Record, N., 2013. Selection and validation of a complex fishery model using an uncertainty hierarchy. Fish. Res., 143, 5766.

Lett, C., Rose, K.A., Megrey, B., 2009. Biophysical models. In: Checkley, D.M., Alheit, J., Oozeki, Y., Roy, C. (Eds.). Climate change and small pelagic fish. Cambridge University Press, Cambridge, UK, pp. 88-111.

Lo, N.C.H., Macewicz, B.J., Griffith, D.A., 2010. Biomass and reproduction of Pacific sardine (Sardinops sagax) off the Pacific northwestern United States, 2003-2005. Fish. Bull. 108, 174-192.

Motos, L., Uriarte A., Valencia, V., 1996. The spawning environment of the Bay of Biscay anchovy (Engraulis encrasicolus L.). Sci. Mar. 60 (Supl. 2), 117-140.

Okunishi, T., Yamanaka Y, Ito S-I., 2009. A simulation model for Japanese sardine (Sardinops melanostictus) migrations in the western North Pacific. Ecol. Model. 220, 462-479.

Okunishi, T., Ito, S-I., Hashioka, T., Sakamoto, T.T., Yoshie, N., Sumata, H., Yara, Y., Okada, N., Yamanaka, Y., 2012a. Impacts of climate change on growth, migration and recruitment success of Japanese sardine (Sardinops melanostictus) in the western North. Climate change 115 (3-4), 485-503.

Okunishi, T., Ito, S-I., Ambe, D., Takasuka, A., Kameda, T., Tadokoro, K., Setou, T., Komatsu, K., Kawabata, A., Kubota, H., Ichikawa, T., Sugisaki, H., Hashioka, T., Yamanaka, Y., Yoshie, N., Watanabe, T., 2012b. A modeling approach to evaluate growth and movement for recruitment success of Japanese sardine (Sardinops melanostictus) in the western Pacific. Fish. Oceanogr. 21, 44-57.

Petitgas, P., Massé, J., Grellier, P., Beillois, P., 2003. Variation in the spatial distribution of fish length: a multi-annual geostatistics approach on anchovy in Biscay, 1985-2002. ICES Document, CM 2003/Q:15.

Petitgas, P., Beillois P., Grellier, P., Massé, J., 2004. On the importance of adults in maintaining population habitat occupation of recruits as deduced from observed schooling behaviour of age- 0 anchovy in the bay of Biscay. ICES CM 2004/J:1.

Petitgas P. (Ed.), 2010. Life cycle spatial patterns of small pelagic fish in the Northeast Atlantic. ICES Cooperative Research Report No. 306, 93 pp (http://www.ices.dk/pubs/crr/crr306/CRR\%20306Web.pdf).

Petitgas, P., Doray, M., Massé, J., Grellier, P., 2011. Spatially explicit estimation of fish length 
histograms, with application to anchovy habitats in the Bay of Biscay. ICES J. Mar. Sci. 68, 2086-2095.

Petitgas, P., Rijnsdorp, A.D., Dickey-Collas, M., Engelhard, G.H., Peck, M.A., Pinnegar, J.K., Drinkwater, K., Huret, M. Nash, R.D.M., 2013. Impacts of climate change on the complex life cycles of fish. Fish. Oceanogr. 22, 121-139.

Planque, B., Bellier, E., Lazure, P., 2007. Modelling potential spawning habitat of sardine (Sardina pilchardus) and anchovy (Engraulis encrasicolus) in the Bay of Biscay. Fish. Oceanogr. 16, 1630.

Planque, B., Loots, C., Petitgas, P., Ulf Lindstrøm, U., Vaz S., 2011 Understanding what controls the spatial distribution of fish populations using a multi-model approach. Fish. Oceanogr. 20(1), 117.

Politikos, D., Somarakis, S., Tsiaras, K.P., Giannoulaki, M., Petihakis, G., Machias, A., Triantafyllou, G., 2014. Simulating anchovy’s full life cycle in the northern Aegean Sea (eastern Mediterranean): A coupled hydro-biogeochemical-IBM model. Progr. Oceanogr., doi :http://dx.doi.org/10.1016/j.pocean.2014.09.002.

Poulet, S.A., Laabir, M., Chaudron, Y., 1996. Characteristic features of zooplankton in the Bay of Biscay. Sci. Mar. 60 (Supl. 2), 79-95.

Railsback, S.F., Lamberson, R.H., Harvey, B.C., Duffy, W.E., 1999. Movement rules for individualbased models of stream fish. Ecol. Model. 123, 73-89.

Rose, K.A., Fiechter, J., Curchitser, E.N., Hedstrom, K., Bernal, M., Creekmore, S., Haynie, A., Ito, S-i., Lluch-Cota, S., Megrey, B.A., Edwards, C.A., Checkley, D., Koslow, T., McClatchie, S., Werner, F., MacCall, A., Agostini, V., 2015. Demonstration of a Fully-Coupled End-to-End Model for Small Pelagic Fish Using Sardine and Anchovy in the California Current. Progr. Oceanogr., doi: http://dx.doi.org/10.1016/j.pocean.2015.01.012.

Taylor, K., 2001. Summarizing multiple aspects of model performance in a single diagram. J. Geophys. Res.-Atmos. 106 (D7), 7183-7192.

Tu, C.Y., Tseng, YE., Chiu TS., Shen, ML., Hsieh, CH., 2012. Using coupled fish behaviorhydrodynamic model to investigate spawning migration of Japanese anchovy, Engraulis japonicus, from the East China Sea to Taiwan. Fish. Oceanogr. 21(4), 255-268.

Uriarte, A., Prouzet, P., Villamor, B., 1996. Bay of Biscay and Ibero Atlantic anchovy populations and their fisheries. Sci. Mar. 60, 237-255.

Wang, Y., Wei, H., Kishi, M.J., 2013. Coupling of an Individual-Based Model of Anchovy with Lower 
Trophic Level and Hydrodynamic Models. J. Ocean Univ. China 12, 45-52.

Ward, T.M., Staunton-Smith, J., Hoyleb, S., Halliday, I.A., 2003. Spawning patterns of four species of predominantly temperate pelagic fishes in the sub-tropical waters of southern Queensland. Estuar. Coast. Shelf. Sci. 56, 1125-1140.

Watkins, K.S., Rose, K.A., 2012. Evaluating the performance of individual-based animal movement models in novel environments. Ecol. Model. 250, 214-234.

Watkins, K.S., Rose, K.A., 2014. The effects of spatial and temporal resolution in simulating fish movement in individual-based models. Trans. Am. Fish. Soc. 143, 1143-1160.

Woillez, M., Poulard, J-C., Rivoirard, J., Petitgas, P., Bez, N., 2007. Indices for capturing spatial patterns and their evolution in time, with application to European hake (Merluccius merluccius) in the Bay of Biscay. ICES J. Mar. Sci. 64, 537-550.

Xu, Y., Chai, F., Rose, K.A., Ñiquen M.C., Chavez, F.P., 2013. Environmental influences on the interannual variation and spatial distribution of Peruvian anchovy (Engraulis ringens) population dynamics from 1991 to 2007: A three-dimensional modelling study. Ecol. Model. 264, 6482. 